\title{
YAWNING
}

\author{
BY \\ JACQUES BARBIZET \\ From the Hospital of Saint Antoine, Paris
}

Halfway between a reflex and an expressive movement yawning is a very commonplace phenomenon.

Perhaps this is the reason why one searches in vain for a paper on this subject in text-books of contemporary physiology or psychology and that one must be content with the brief definition in the dictionary that "yawning is a deep inspiration made voluntarily with a wide open mouth".

Many authors since Hippocrates, who seems himself to have been interested in the question, have studied either certain aspects or the whole problem. An excellent historical survey of the past knowledge about yawning may be found in the thesis of Trautmann (1901), where are reported the opinions of Galen, Oribase, Sanctorius, Fernel (1610), Kruger (1627), Sennert (1666), Boerhave (1680), Gartner (1736), Albertini (1737), Gunz (1738), Czerniewski (1749), Buchner (1758), Roederer (1759) Haller (1766), Walther (1775) Double (1817), Adelon (1821), Rothmund (1824), Richerand (1825), Muller (1851), Monneret (1861), Longet (1868), and Dechambre and Charcot.

In the twentieth century more papers have been written, among others by Hauptmann (1920), Dumpert (1921), Mayer (1921), Insabato (1928), Peiper (1932), Moore (1942), and Salmon (1948). Two good critical reviews are those by Heusner (1946) and Boudouresques (1950).

The zoologists have not remained indifferent, and they teach us that yawning may be observed in the primates and the carnivores. It is often accompanied by stretching. It is not observed in herbivores. It is difficult to specify its significance, and the connexion between yawning and the movement of opening the mouth that may be observed in fishes, reptiles, and amphibians. The same may be said of the movements made by the bird's beak accompanied by flapping of the wings. Therefore our study shall remain limited to man.

\section{Analysis of Yawning}

Yawning is an involuntary, paroxysmal breathing movement. It is a motion unfolding itself in a certain order, wherein three phases may invariably be distinguished : the first one is active and inspiratory; the second phase corresponds to the acme; the third is passive and expiratory. Their respective duration is about 1.5 to $4 \mathrm{sec}$. each. An average yawn lasts from 4 to $7 \mathrm{sec}$.

An analysis of the subject's movements may be made by a clinical survey or by the study of radiographs taken every half second, as we have done at St. Antoine Hospital with Dr. Chalut.

In the first phase we see the progressive opening of the mouth, the dilatation of the pharyngo-larynx and of the thorax, and the lowering of the diaphragm. The opening of the mouth is very slow, and the mouth is still half open when the dilatation of the pharynx and the larynx is already at its maximum.

The lowering of the neck's air axis is obvious from simple inspection, which shows the lowering of the thyroid cartilage. A radiograph shows that the body of hyoid bone, which stands at rest at the level of C.2-3 vertebrae goes down to C.6-7, and explains the tongue's situation as it is pulled backward and downward, the tip going well away from the teeth. The dilatation of the glottis and the abduction of the vocal cords can be verified by a laryngoscopic examination sufficiently long continued to catch a spontaneous yawn. The radiographs have shown that the dilatation of the pharynx is enormous and surprising, for it increases to three or four times its normal size (Fig. 1 and 2). The pharynx, larynx, and trachea, as well as the bronchial tubes, appear very dilated on the plates. While the opening of the mouth and the deep inspiration may be observed in many cases apart from yawning, the enormous expansion of the pharynx with the lowering of the hyoid bone and of the tongue is peculiar to yawning.

It is to be noted that the inspiratory sound observed in yawning is produced in the palate and the throat's isthmus. It is not a glottal noise, the glottis being dilated to its utmost at this phase.

The second phase of yawning corresponds to the acme of the mouth's opening and to that of the pharyngeal and thoracic dilatation. Certain pre- 

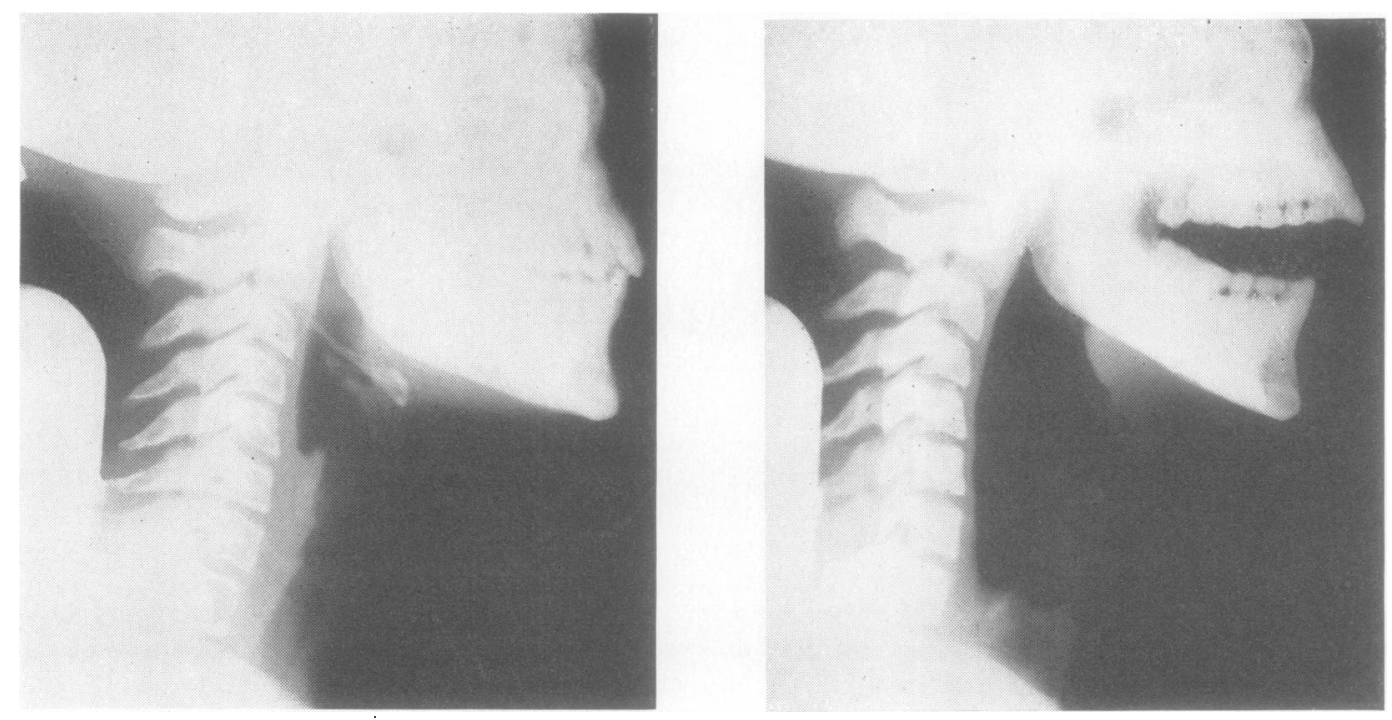

FIGS. 1 and 2.-Radiographs of the pharynx before and during yawning.

disposed subjects may even at this point dislocate the jaw. At this moment appear the facial modifications which began at the end of the first phase. Contraction of the lip dilators exaggerates the mouth's opening and contraction of the eyelids causes a partial or even a total occlusion of the eyes. The nostrils are dilated. The skin at the base of the nose wrinkles and the eyebrows are lifted. At this phase there may also be a degree of tonic contraction of the extensor muscles of the neck and of the trunk, and may extend to include hyperextension of the limbs. The stretching, which is far from constant, has the result of increasing the thoracic capacity. Tears may be secreted, and less frequently saliva.

The third phase is passive. The inspiration ceases abruptly. Expiration is slow and noisy, followed by the sound " aah" originated by the larynx. The pharynx goes back to its normal size, the mouth closes itself, and the face resumes its usual aspect.

This group of complex and synergic motions constitutes yawning. However, yawning may be accompanied by other motions emphasizing or minimizing its action. Yawning may be exaggerated and emphasized by stretching of the limbs, or by a modulation of breathing, or by the execution of rhythmic lateral motions of the mandibles.

Yawning can also be repressed to a certain extent in circumstances where it would constitute bad behaviour; the subject puts his hand before his mouth. He can also repress a yawn by stopping the mouth's opening and controlling the inspiratory motion. But, in spite of efforts, yawning is often betrayed by such a gesture, and a stifled yawn does $\omega$ not escape a careful observer. In this case yawning $\underset{\omega}{\mathcal{E}}$ may be reduced to the action of the pharynx, which? once more shows the importance of this phase. $\stackrel{2}{2}$

Certain physiological observations have been $\square$ made during yawning, but they offer small reward 0 c There may be a slight acceleration of the heart in of the inspiratory phase with a fall in the index of $\overrightarrow{0}$ capillary oscillations in the finger tips. This phe nomenon is of no great importance, as it may also be observed during deep inspiration (Heusner, 1946). An E.E.G., if performed in the act of yawning, cannot be interpreted owing to interference by movements and muscle action.

It is noteworthy that a yawn is rarely isolated. It usually occurs in fits of two or three. The intensity of the yawn often increases, and each yawn is separated by a few regular breaths. Sometimes, the yawns will be repeated, irregularly, during several minutes.

\section{Yawning and Stretching}

These two actions are often but not always associated. Stretching is connected with the second phase of yawning. Infants and animals stretch and yawn often at the same moment. In adults, stretching is usually observed in the period of awakening. The association of these two motions is far from constant. Yawning, even excluding cases where stretching is repressed by good manners, is often isolated. Likewise, stretching after a long period in the same position is not accompanied by a yawn. These facts allow us not to give quite the same physiological 
interpretation to these motions, especially as we shall see in the case of their functional value.

\section{The Cause of the Yawn}

There are numerous causes, which may be classified in three categories, physiological, pathological, and experimental.

Physiological.-Drowsiness must be mentioned first; men and animals yawn when they are sleepy. They yawn also when they emerge from sleep. Some persons are subject to yawning and stretching when they awake.

Boredom is a frequent cause. It can be the consequence of different circumstances-a dull talk, a tedious lecture, a wearisome book. Weariness is intimately connected with a lack of interest fundamental to the genesis of yawning.

Seeing others yawning is infectious. "Interdum tamen sola imaginatio ossitationis causa est. Cum enim qui videt alium oscitare, ipse quoque ad oscitandum invitatur" quoted Sennert in 1666. "One yawn brings seven," is a popular saying.

It is easy to make oneself yawn. Four or five deep inhalations with a wide open mouth, imitating spontaneous yawning, provoke yawning. Once the spontaneous yawn has begun, it will seldom remain isolated, and during the following quarter of an hour will be followed by new isolated yawns or by a fit of yawning.

Hunger or, the contrary, the plenitude after a heavy meal, are generally admitted as inducing yawning. In the second case yawning is associated with drowsiness. Certain plethoric patients seek medical advice for these post-prandial yawns.

Yawning is frequent in certain circumstances, such as physical weariness or pregnancy.

Pathological.-Yawning is commonly observed in lesions of the brain-stem. It can also be seen in intrinsic lesions (haemorrhage, softening, tumours), and in compressions (posterior fossa tumours). It is noteworthy to recall that drowsiness is a symptom of peduncular softening (Lhermitte).

If yawning is commonly observed in hemispheric tumours, especially frontal and temporal tumours, and in hemispheric haemorrhage, it is probably due to indirect compression of the brain-stem provoked by intracranial hypertension or a temporal herniation. In such cases a yawn serves as an indication of a brain-stem lesion and bears a bad prognosis.

In the course of diffuse lesions of the brain, yawning is not infrequent. It has been observed in cases of alcoholic encephalopathy and of general paralysis of the insane.

Yawning is frequent in respiratory sequelae to encephalitis lethargica, together with sighs and spasmodic hiccup. Sicard and Paraf (1921) and Turner and Critchley (1925) mention spasmodic yawning and gaping. Choreics also yawn. Yawning can be observed in certain varieties of epilepsy. Wilson (1940) interprets yawning as an "aura " of visceral crisis.

Penfield and Jasper (1954) mention two observations of yawning as an element of autonomic diencephalic seizures. They cite the case of a woman of 29 with a large astrocytoma occupying the whole left temporal lobe and the lower portion of the corpus striatum, whose fits started abruptly with occipital pain accompanied by yawns and hiccups while at the same moment the left arm and the left side of the mouth became numb. The fit ended with a need to urinate.

Yawning has been described very often and with many details as a manifestation of hysteria (Charcot, Dejerine).

Salmon (1948) points out that fits of yawning may be a sign in myasthenia gravis and quotes one of his personal cases and one of Albertoni's. He indicates the action of prostigmine in stopping yawning. Yawning is also noted in the course of anaemia, haemorrhage, and shock, and during pyrexia, as well as in digestive disturbances, though no one has tried to explain its mechanism in this case.

Yawning and Cerebral Stimulation.-A comparison is possible between the natural causes of yawning and yawning created experimentally by intracerebral stimulation, but we do not know of any research work. On the other hand, yawning has been studied and noted in certain protocols. Hess (1938), by stimulating the intralaminar substance of the thalamus and the posterior subthalamus, has induced sleep in cats after fits of yawning. The experiments of Passouant, Passouant-Fontaine, and Cadilhac (1956) on the stimulation of the rhinencephalon, and particularly of Ammon's horn, also mention yawning. The induced crisis has three phases: during stimulation, reaction of escape, and during the postdischarge period, uneasiness with a diminution of watchfulness. In the third phase the animal stands, licks itself, purrs. This manifestation of well-being lasts a few minutes, and sometimes the animal lies down, stretches, yawns and goes to sleep.

Sleep may start three or four minutes after the discharge. An E.E.G. of the hippocampus shows that it is preceded by sharp waves with increased voltage.

It is obvious in this case that yawning is only a late and indirect manifestation of stimulation. We must remember, however, that it is integrated in a behaviour of well-being and sleepiness opposed to the reaction of escape simultaneous with stimulation. 
The fact that yawning may be observed during the stimulation of the rhinocephalon or hypothalamus, formations which are functionally and intimately joined with the reticular activating system, must be emphasized.

Linked Yawning and Stretching.-In normal subjects yawning and stretching may be independent of one another, but in some pathological conditions they are tightly linked. Dumpert (1921) and Lewy (1921) refer to the clinical observation of hemiplegic patients in whom yawning was attended by stretching the paralysed arm. Heusner (1946) also mentions spontaneous stretching of the paralytic arm provoked by a yawn.

\section{Physiology of Yawning}

While the clinical aspects and the determining causes of yawning are well known, its physiological mechanism is no better known than its significance.

Besides the fanciful interpretations already mentioned, a certain number of theories have been brought forward that may be classified in two groups according to whether the yawn is a secondary or a primary disturbance.

In the first group yawning is considered as a mechanism of regulation, just as shivering is considered as an automatic reaction opposed to the cooling of the organism. No agreement has been reached, however, either on the nature or on the mechanism of this regulation.

Hauptmann (1920) suggested that yawning and stretching were opposed to muscular hypotonia which, like boredom, is the consequence of the inactivity of superior brain centres. Salmon (1948) maintains that yawning is an automatic reaction of the respiratory muscles caused by hypotonia of the respiratory bulbar nerves and by the hypotonia that follows sleep. But Dumpert (1921) went farther in this hypothesis. He considers that yawning occurs when the brain circulation is not sufficient to maintain wakefulness and vigilance. Yawning and stretching should increase venous circulation to the heart first by compressing the veins of the trunk and the limbs as well as the splanchnic veins; secondly, by diminishing the intrathoracic pressure. The resulting venous hypertension increases the cardiac output (Bainbridge's reflex) and consequently improves arterial irrigation. The brain circulation benefits especially, and, further, the sensory stimuli from the stretched muscles produces, according to Dumpert, systemic vasoconstriction and vasodilatation of cerebral arteries. Stretching, and to a lesser degree yawning, might thus produce an increase of blood circulation sufficient for the maintenance of wakefulness.
Among the functional theories of yawning, the hypothesis quoted by Heusner (1946) of a secretion of thyroxin determined mechanically by the compression of the thyroid gland during yawning shouldeo be mentioned.

Beside these resolutely finalist theories, some authors neglect the physiological consequences of $\frac{\bar{T}}{\mathrm{~T}}$ yawning and consider it as an accident connected $\stackrel{0}{5}$ with cerebral strain (Mayer 1921), just as crying and laughing are the expressions of pain or joy.

For Peiper (1932), yawning is a transitory disorder of the respiratory centres, weariness producing $a \subseteq$ decrease of the excitability of the superior respiratory $\frac{\bar{\sigma}}{2}$ centres liberating an underlying centre for yawning. $\Phi$

These theories, without being completely opposed, are based on unverified or disproved physiological ${ }^{\infty}$ hypotheses, such as the increase of venous pressure $\vec{O}$ during yawning or the decrease of the cerebral blood $\overrightarrow{-}$ flow when wakefulness ceases. They still leave ${ }_{\sigma}$ unexplained certain aspects of the psychomotor reflex described as yawning.

In the light of contemporary knowledge of psychophysiology, it is possible to attempt an explanation $\vec{\omega}$ of the mechanism of yawning, while neverthelegsin underlining the gaps open to further research.

\section{The Mechanism of Yawning}

Yawning is a complex, involuntary, and paroxy $8-c$ mal act. Under the influence of a certain number of $\frac{2}{9}$ facts, a brief $(4 \mathrm{sec}$. to $7 \mathrm{sec}$.) motor activity tak place, bringing into play a great number of thoract cervico-facial muscles. This suggests a critical activity spreading from one place to another in a given neuronal circuit. With the knowledge of the muscles participating in yawning, it is possible to state that the motor nuclei involved are located in the bulb and in the cervical cord. It is therefore $\stackrel{\Phi}{\varrho}$ possible to state that yawning, or more exactly the $\overrightarrow{\vec{D}}$ motion of the yawn, is connected with a paroxysmal 3 discharge involving a certain number of motor $\supsetneq$ nuclei situated in the bulb and in the cervical cord. The extension of this discharge to the nuclei of the trunk and the limb muscles induces stretching.

It seems impossible to specify whether there exists $:$ a hierarchy in this neuronal structure which would 3 . allow us to locate a "centre of yawning". But, on 8 the other hand, we may note that this structure has $₹$ a close relationship to both the reticular formation 을 and the cerebral cortex. The brain-stem reticular formation appears, according to a large number of $\frac{D}{0}$ studies of Magoun (1950) and of Moruzzi and Magoun (1949), to be capable of modifying the cen- $N$ tral excitatory state, and thus of controlling the N degree of alertness. It determines the level of con- N sciousness in its arousal capacities, alertness declining 
in sleep and in pathological states related to sleep (drowsiness, torpor), and disappearing only in deep coma, and, on the contrary, increasing in varying degrees according to the intensity of stimulation and, probably, to the extent of the nervous mechanism set in motion.

Participation of the cerebral cortex cannot be contested when yawning is the result of complex psychic activities such as imitation or boredom. It is interesting to recall in this connexion the experiences of French, Hernandez-Peon, and Livingston (1955) showing that efferent pathways issuing from the cerebral cortex appear to project down to the reticular formation.

If we maintain this hypothesis, which should be verified, particularly by recording the neuronal activity of the nuclei set in motion by yawning with intrabulbar electrodes, the standard E.E.G. being uninformative, we must answer the following question: Which are the responsible factors in the paroxysmal discharge in this bulbo-medullary motor structure ?

Circulatory and Humoral Factors.-These must first be discussed because they have generally been invoked though without any accurate experimental data.

The frequency of the yawn in the course of anaemia or circulatory insufficiencies invokes the possibility of bulbar anoxia or modification of the $\mathrm{CO}_{2} / \mathrm{O}_{2}$ ratio. We lack precise facts on this subject, but we can observe that voluntary apnoea, even if it lasts some time, does not cause yawning. There is no proof that a slight variation of bulbar circulation will carry with it anoxia. On the contrary, we know the part played by Hering's nerve and the carotid sinus in the regulation of cerebral circulation as well as the constancy of this circulation under physiological conditions. Furthermore, one does not observe yawning when the central cerebral circulation is insufficient, as in the paroxysmal fits of bradycardia in the course of the Stokes-Adams syndrome.

Some authors also mention the part taken by humoral modifications. Yawning and post-prandial drowsiness may be attributed to an alkalotic wave or a discharge into the blood of polypeptids or lipids of digestive origin. It could also be produced by intermediary metabolites due to muscular strain. Crämer (1924), noting the frequency of yawning in patients with colitis, assumed that it was due to an auto-intoxication by bacteriological toxins produced in the bowel. In fact, the existence of an endogenous origin has not been proved any more than that of an endogenous hypnotic substance.

Pharmacology provides, on the contrary, drugs predisposing to the appearance of yawning and of drowsiness, as is the case with morphine and hypnotics. The action of these substances on the reticular formation is well known, whereas caffeine and amphetamine have an opposite effect. In conclusion, if yawning can be induced by pharmacological means, there is no formal proof of the part taken by circulatory or humoral disturbances in the genesis of yawning.

It must be noted that if such disturbances exist, which remains possible and must be the subject of further studies, they could only be an adjuvant cause, their duration clearly exceeding the duration of yawning, which may or may not appear in instances such as after meals, according to the psychological condition of the subject.

Psycho-sensorial Factors.-Spontaneous yawning must be distinguished from yawning by imitation. Both are influenced by the surrounding circumstances, but in different ways.

Spontaneous yawning occurs in particular physiological circumstances such as weariness or sleepiness. In these cases, the subject lacks interest in his surroundings and spontaneous thought diminishes. On the contrary, one does not yawn and even if one is drowsy, one awakes if a new stimulus abruptly appears. It may be physical stimulation or affective shock which rouses attention. People do not yawn at the very moment they learn the result of an important examination or the news of an accident to a relative. Yawning only occurs in psychological conditions of indifference or lack of interest in surroundings.

Knowing the part played by the reticular formation in the mechanism of wakefulness, we propose the following hypothesis. Yawning is an integrated discharge in a bulbo-reticular motor structure occurring at a particular level of activity of the reticular formation corresponding to a decrease of wakefulness preceding sleep. This hypothesis, which is in agreement with neurophysiological and pharmacological principles, explains why yawning may be observed when a subject begins to sleep as well as when he awakens. In our opinion, yawning appears as a physical manifestation of a drop in wakefulness. This paroxysmal motor discharge may be compared with the muscular hypotonia observed during sleep. It is the expression of a mode of being and does not constitute a reaction against it. It should not play any physiological part. In fact, yawning, as we know, induces yawning and does not induce wakefulness. Yawning should be distinguished from stretching, which perhaps has the function of setting wakefulness in motion.

Yawning by imitation may occur in certain 
circumstances of release of interest, but the fact that it can be induced shows that we maintain a certain degree of consciousness in our surroundings which involves some participation of our system of wakefulness. The infectiousness of yawning is only one example of the numerous acts caused by imitation, often quite unconsciously, for instance, repeating a tune, raising or lowering one's voice according to one's interlocutor, answering a grin by another grin, or a smile by a smile. In the same way, some expressive acts such as laughing or crying are infectious in certain circumstances. There is still much to discover in the mechanism of association. However, the possibility of associating two stimulations, two ways of behaving, two ideas, is at the basis of learning. Infectious yawning is just one particular case in a series of imitative gestures.

It is also difficult to interpret the mechanism which determines a real, spontaneous, irrepressible yawn after a fit of false yawning. The passage of a voluntary act to a paroxysmal and involuntary one is difficult to interpret on purely associative grounds, and one may wonder to what extent the fact of yawning voluntarily, by a mechanism which remains to be described accurately, has not modified neuronal excitability, thus facilitating the paroxysmal and involuntary discharge.

Psycho-social Significance of Yawning.-Let us eliminate from this discussion infectious yawning, an imitative gesture which is proof of a normally suggestible subject and of his psychological irresponsibility, and let us return to spontaneous yawning.

Without any physiological usefulness, spontaneous yawning has still a psychological significance: it shows lack of interest. This psycho-physiological conception carries with it certain considerations on the social circumstances under which yawning occurs.

Yawning has an expressive mimic value as long as it indicates indifference and boredom. The interest or lack of interest that we feel for our surroundings certainly depends on the nature of the surroundings. The interest of the subject will be very differently stirred according to whether he is lying peacefully in silence and in darkness, or whether experiencing sensory or psychic stimulation. This applies to infants as well as to adults. For the latter, however, the interest he feels for the exterior world depends largely on his personality and his former experience. Interest is conditioned by different factors, such as family, school, profession, social position. For instance, a conversation on an unfamiliar topic, or concerning an unknown person, causes lack of interest. The same could be said of a

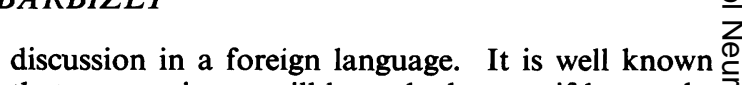
that a connoisseur will bore the layman if he speaks at length on an esoteric subject. To a certain extent $\stackrel{\mathscr{C}}{=}$ it is easy to know when the subject will please or bore, one's taste representing exactly what one is interested in. The intimate connexion between $\stackrel{\Im}{\Im}$ interest and personality explains the expressive value of yawning, which appears as the mark of unconcern $\vec{z}$ and disinterest. It may be said that yawning is to boredom what the gestures of laughing and crying $\stackrel{5}{\rightarrow}$ are to joy and sorrow.

This interpretation of the significant value of $\frac{\bar{O}}{\bar{D}}$ yawning agrees with the popular opinion that $\frac{\bar{\rho}}{\sqrt{3}}$ yawning is a symptom of boredom. The fact that $\stackrel{\curvearrowright}{\varrho}$ it is polite to put one's hand before one's mouth when yawning, that is, to hide a yawn, a habit $\rightarrow$ learned in childhood and which becomes automatic? to the point of being an integral part of the yawn, $\vec{\omega}$ is an implicit acknowledgement of the social sig- $\stackrel{\mathscr{\omega}}{\stackrel{D}{ }}$ nificance of that motion expressing weariness and refusal, which it is better to dissimulate.

It is possible that in putting forward a digestive ${ }_{-}$ trouble as an explanation of yawning the subjeet $\dot{\omega}$ unconsciously tries to hide the real cause, boredon. As an involuntary expressive gesture, yawning, however, a conscious phenomenon to which, in th course of its automatic development, voluntafy modulations may be added. For instance, a supe pressed yawn shows an endeavour to dissimulage boredom. On the other hand, an emphasized yaw $\stackrel{\rho}{?}$ long and noisy, proves in an unequivocal manne that the subject wants to show his weariness or even his aggressive attitude to a situation for which he does not feel any interest.

\section{Summary}

The different phases of the yawn are described, $\cong$ while the physiological and pathological causes are $\overrightarrow{0}$ considered.

The classical theories of yawning are discussed.

The following views are put forward:-

(a) The yawn is connected with an integrated discharge in a bulbo-cervical motor complex which appears at a certain level of excitability of the con- $\frac{0}{3}$ sciousness arousal system (reticular brain-stem formation) corresponding to the lessening of alertness preceding sleep.

(b) This particular state of alertness depends on 윽 sensory stimulations received from the surroundings. $\rightarrow$ It can also be induced experimentally by intracerebral electric stimulation or by certain drugs (hypnotics).

The part played by endogenous factors (circu- $\Omega$ latory or humoral), though often discussed, has $\mathbb{O}$ never been proved.

(c) On physiological grounds, yawning appears 
as the physical manifestation of a lowering of wakefulness, and does not seem to have any physiological function.

(d) From the psychological point of view, yawning by imitation may be considered as one particular case in the series of imitative gestures. Spontaneous yawning, on the contrary, may be included among the expressive gestures. Interest as well as lack of interest is intimately connected with the personality. Yawning, which expresses boredom, unconcern, and indifference to certain circumstances, has the value of a refusal, and even in certain cases of an unconsciously or consciously aggressive attitude.

\section{REFERENCES}

Boudouresques, J. (1950). Baillement, p. 3. Encyclopedie NeuroChirurgicale-Neurologie-. T.1-17012 E.
Crämer, F. (1924). Arch. Verdau.-Kra., 33, 149.

Dumpert, V. (1921). J. Psychol. Neurol. (Lpz.), $27,82$.

French, J. D., Hernandez-Peon, R., and Livingston, R. B. (1955). J. Neurophysiol., 18, 74 .

Hauptmann, A. (1920). Neurol. Zbl., 39, 781.

Hess, W. R. (1938). Das Zwischenhirn und die Regulation von Kreislauf und Atnung, Vol. 1, p. 124. Thieme, Leipzig.

Heusner, A. P. (1946). Physiol. Rev., 26, 156.

Insabato, L. (1928). Arch. gen. Neurol. Psichiat., 9, 125.

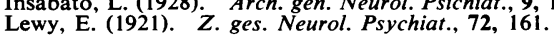

Magoun, H. W. (1950). Physiol. Rev., 30, 495.

Mayer, C. (1921). Z. Biol., 73, 101.

Moore, J. E. (1942). J. gen. Psychol., 27, 189.

Moruzzi, G., and Magoun, H. W. (1949). Electroenceph. clin. Neurophysiol., 1, 455.

Passouant, P., Passouant-Fontaine, T., and Cadilhac, J. (1956). Rev, neurol. (Paris), 94, 292.

Rev. neurol. (Paris), 94, 292.
Peiper, A. (1932). Dtsch. med. Wschr., 58, 693.

Penfield, W., and Jasper, H. (1954). Epilepsy and the Functional Anatomy of the Human Brain. p. 417. Churchill, London.

Salmon, A. (1948). Presse méd., 56, 739.

Sicard, J. A., and Paraf, A. (1921). Bull. So:. méd. Hôp., Paris, 45, 232.

Trautmann, R. F. A. (1901). Le baillement. Thèse de Médecine, Bordeaux (bibliography before 1900)

Turner, W. A., and Critchley, M. (1925). Brain, 48, 72.

Wilson, S. A. K. (1940). Textbook of Neurology, Vol. 1, p. 121 and Vol. II, pp. 1223 and 1507. Butterworth, London. 